\title{
Ultradian Cycles of Mood in Normal and Depressed Subjects
}

Donald P. Hall Jr., M.D.

Combat Stress Center, Fort Bragg, N.C.

David Benedek M.D.

Walter Reed Army Medical Center, Washington, D.C.

Audrey Chang

Walter Reed Army Medical Center, Washington D.C.

Follow this and additional works at: https://jdc.jefferson.edu/jeffjpsychiatry

Part of the Psychiatry Commons

Let us know how access to this document benefits you

\section{Recommended Citation}

Hall, Donald P. Jr., M.D.; Benedek, David M.D.; and Chang, Audrey (1996) "Ultradian Cycles of Mood in Normal and Depressed Subjects," Jefferson Journal of Psychiatry. Vol. 13 : Iss. 1 , Article 3.

DOI: https://doi.org/10.29046/JJP.013.1.002

Available at: https://jdc.jefferson.edu/jeffjpsychiatry/vol13/iss $1 / 3$

This Article is brought to you for free and open access by the Jefferson Digital Commons. The Jefferson Digital Commons is a service of Thomas Jefferson University's Center for Teaching and Learning (CTL). The Commons is a showcase for Jefferson books and journals, peer-reviewed scholarly publications, unique historical collections from the University archives, and teaching tools. The Jefferson Digital Commons allows researchers and interested readers anywhere in the world to learn about and keep up to date with Jefferson scholarship. This article has been accepted for inclusion in Jefferson Journal of Psychiatry by an authorized administrator of the Jefferson Digital Commons. For more information, please contact: JeffersonDigitalCommons@jefferson.edu. 


\title{
Ultradian Cycles of Mood in Normal and Depressed Subjects*
}

\author{
Donald P. Hall ${ }^{1}$ Jr., M.D., David Benedek ${ }^{2}$ M.D. \\ and Audrey Chang ${ }^{2}$
}

\begin{abstract}
Objective: To study ultradian cycles of mood in four inpatient groups.

Method: We assessed the mood of depressed and nondepressed subjects, on an hourly basis, between 7:00 a.m. and 10:00 p.m. for two consecutive days using a visual analog scale of mood. Hourly mood scores for each group were plotted against time.

Results: We found ultradian cycles with mean lengths of 3-4 hours in all groups. The major depressive episode and adjustment disorder depression groups, however, had ultradian cycles of significantly greater amplitude than ward staff.

Conclusions: Depressed patients demonstrate greater amplitude in ultradian cycles of mood than nondepressed subjects.

Ultradian cycles (cycles $<24$ hours in length) have been demonstrated in a variety of physiological factors and mental functions of interest to psychiatry. Normal subjects have been shown to demonstrate ultradian cycles of cognitive performance efficiency $(1,2)$, short term memory $(3)$, sleep-wakefulness $(4,5)$ and $\operatorname{mood}(6,7)$. The ninety minute cycle of rapid-eye-movement sleep (REM) is probably the most intensively studied ultradian cycle in the area of psychiatry. This cycle has been reported to be disrupted in depressive disorders $(8,9)$. In a recent exploratory study by one of the authors (D.H.) and others, it was demonstrated that depressed patients also exhibit an abnormal ultradian cycle of mood (7). It was reported that a depressed group exhibited ultradian cycles of significantly greater amplitude than a nondepressed group. Based on our review of the literature, this was the first reported study of ultradian cycles of mood in depression.

In the present study, we test the reliability of an exploratory study which found ultradian cycles of greater amplitude in depressed group than in a non-depressed group (7). In this follow-up study, we have extended mood assessment over two days in order to investigate day to day stability of cycles, and have included non-depressed and adjustment disorder with depressed mood patient groups to assess specificity of the finding.
\end{abstract}

\footnotetext{
${ }^{1}$ Submitted from Combat Stress Center, Fort Bragg, N.C. and ${ }^{2}$ Walter Reed Army Medical Center, Washington, D.C.

*The first author awarded the American Psychiatric Association's 1994 Dista Products Resident Research Award based on this manuscript.
} 


\section{METHOD}

Subjects

This investigation was performed on psychiatric inpatients and ward staff volunteers from the inpatient psychiatric units of Walter Reed Army Medical Center (WRAMC). Two control groups were utilized: one group of ward staff (including medical students, psychiatric residents, and nursing personnel) and a second group of non-depressed psychiatric inpatients (primarily composed of patients recovering from thought disorders). Depressed subjects were selected according to the following inclusion criteria: presence of a DSM IIIR-defined major depressive episode or adjustment disorder with depressed mood, continuous presence on the WRAMC inpatient psychiatric wards for at least two consecutive days and a willingness to participate. Potential subjects were excluded from each group if concurrently diagnosed with borderline or histrionic personality disorder, Axis III conditions believed to be related to their mood disorder, recent history of hallucinations or thought disorders, or evidence of withdrawal from psychoactive substances. No subjects reported a history of premenstrual syndrome. The four groups consisted of: 12 ward staff, 6 non-depressed psychiatric patients, 8 patients with adjustment disorder with depressed mood, and 12 patients with major depressive episodes (two melancholic and three with psychotic features). Male to female ratios were 10:2, 3:3, 4:4, and 4:8 for these groups, respectively. Mean ages are reported in Table 1 . The subjects were not aware of the hypothesis being tested. All subjects gave informed consent.

Assessment of Mood

Mood was assessed for each subject on an hourly basis, between the hours of 7:00 a.m. and 10:00 p.m. on two consecutive days. The hourly mood assessment was

TABLE 1.

\section{Means and Standard Deviations (in parenthesis) for Age, Hamilton Depression Scale (Ham-D), Visual Analog Scale of Mood (VASM), and Intra-Daily Variability of Mood (IDVM) Scores}

\begin{tabular}{lccccccc}
\hline & & & \multicolumn{2}{c}{ Mean VASM Score } & & \multicolumn{2}{c}{ IDVM } \\
Group & Age & Ham-D & Day 1 & Day 2 & & Day l & Day 2 \\
\hline Ward Staff & $27(5.0)$ & $1.0(1.0)$ & $95.7(19)$ & $101(23)$ & & $15.8(9.1)$ & $13.3(7.8)$ \\
& $\mathrm{n}=12$ & $\mathrm{n}=12$ & $\mathrm{n}=12$ & $\mathrm{n}=11$ & $\mathrm{n}=12$ & $\mathrm{n}=11$ \\
Non-depressed & $29(10)$ & $5.0(3.6)^{\mathrm{a}}$ & $95.7(32)$ & $92.7(30)$ & & $19.2(14)$ & $15.5(9.0)$ \\
Patients & $\mathrm{n}=6$ & $\mathrm{n}=6$ & $\mathrm{n}=6$ & $\mathrm{n}=5$ & $\mathrm{n}=6$ & $\mathrm{n}=5$ \\
Adjustment & $33(16)$ & $18(5.4)^{\mathrm{b}}$ & $67.2(24)^{\mathrm{b}}$ & $80.8(29)$ & & $32.3(10)^{\mathrm{b}}$ & $28.8(9.8)^{\mathrm{b}}$ \\
Disorder & $\mathrm{n}=8$ & $\mathrm{n}=6$ & $\mathrm{n}=8$ & $\mathrm{n}=8$ & $\mathrm{n}=8$ & $\mathrm{n}=8$ \\
Major & $37(18)$ & $19(3.4)^{\mathrm{c}}$ & $46.4(24)^{\mathrm{b}}$ & $46.4(24)^{\mathrm{b}}$ & & $20.1(10)$ & $15.8(7.5)$ \\
Depression & $\mathrm{n}=12$ & $\mathrm{n}=12$ & $\mathrm{n}=12$ & $\mathrm{n}=10$ & $\mathrm{n}=12$ & $\mathrm{n}=10$ \\
\hline
\end{tabular}

${ }^{\mathrm{a} p}<0.05$.

${ }^{\mathrm{b}} \mathrm{p}<0.01$.

${ }^{c} \mathrm{p}<0.001$ (significant differences compared to ward staff using Duncan's multiple comparisons test). 
performed using a single question visual analog scale of mood (VASM). The VASM has been demonstrated to be a valid and reliable method for the repeated assessment of mood (10,11). The VASM was composed of a $150 \mathrm{~mm}$ line with the left pole labeled as "worst sad" and the right pole labeled as "best happy." Subjects were instructed to place a mark on this line which best described their current mood state. Each subject's VASM scores (16 hourly scores each day) were averaged to yield a daily mean VASM score for each subject. The amount of mood variation within the day, or intra-daily variability of mood (IDVM), was assessed by calculating the standard deviation of VASM scores for each subject on each study day. Individual IDVM scores were averaged and compared between groups. Each subject was also evaluated using a 17 item Hamilton Depression Scale (Ham-D) (12) on the first morning of testing in order to characterize the severity of depressive symptoms. Non-depressed subjects were excluded for Hamilton Depression Scale scores $>10$. The one-way analysis of variance (ANOVA), followed by the Duncan's multiple range comparison test were used to assess differences between groups for Ham-D, and daily VASM and IDVM scores.

\section{Ultradian Cycles}

Time series plots were developed by plotting time of day (X-axis) versus VASM score (Y-axis) for each subject. Group time series plots were also developed by averaging hourly mood scores for all subjects in each group, for both study days and plotting values in a similar manner. For example, the 7:00 AM point on the major depression group plot represents the average of 22 assessments: 12 subjects on day 1 and 10 subjects on day 2. A comparable method of averaging hourly group mood scores has been used in the study of circadian rhythms of mood (13). In this study, cycle lengths (periods) were determined by measuring the peak-to-peak or trough-totrough distance along the $\mathrm{X}$-axis, beginning with the first complete cycle. Amplitude was determined by measuring peak-to-trough and trough-to-peak distances along the Y-axis. Detailed descriptions of this and other methods of time series data analysis have been reviewed elsewhere (14). Spectral analysis (15) was used to compare data derived from visual inspection to automated computer-derived results. A Hamming window of 3 was used for limited smoothing of time series plots. The Mann-Whitney two sample rank sum test was used to compare the mean ultradian cycle period and amplitude of patient groups to ward staff (16).

\section{RESULTS}

Mood Scales

Group Ham-D score means and standard deviations are listed in Table 1. ANOVA showed significant group differences in Hamilton Depression Scale scores $[F(3,32)=74.72 ; p<0.001]$. Duncan's multiple comparison tests revealed that adjustment disorder and major depression groups had markedly greater Ham-D scores than ward staff $(p<0.001)$. A small yet significantly greater Ham-D score was 
observed in the non-depressed patient group versus ward staff $(p<0.05)$. There was no significant difference between Ham-D scores of adjustment disorder and major depression groups. Approximately 1100 VASM assessments were obtained over 70 subject-days. Group differences in daily mean VASM score were similar to Ham-D findings (Table 1). Comparison of each group's mean intra-daily variability of mood (IDVM), using Duncan's multiple comparison test, revealed that the adjustment disorder group had significantly greater variation of mood scores than both control groups on both days $(p<0.01)$. IDVM in the major depressive episode subjects was not significantly different from controls.

\section{Ultradian Cycles}

Visual inspection of time series plots revealed clearly apparent ultradian cycles in approximately $50 \%$ of individual subject days. These plots, however, were not characteristic of all subjects. Subjects with clear ultradian cycles on day 1 did not demonstrate the same cyclical pattern on day 2. The mood plots of a few subjects (approximately 20\%) demonstrated frequent changes in amplitude and period, and appeared to vary in a random manner. Averaging of hourly group VASM scores, however, yielded time series plots with less variation in cycle length and amplitude (Figure 1). Spectral analysis of group time series data confirmed that the dominant cycle length was 3 hours for staff and 4 hours for the remaining groups. There was no significant difference between groups in ultradian cycle length. Amplitude, however, was significantly greater (based on Mann-Whitney two sample rank sum test) in the major depressive episode group $(u=4.5,25 ; p=0.026)$ and adjustment disorder ( $u=8,34 ; p=0.367)$ groups, when compared to ward staff. The mean amplitude of the non-depressed patient group was not significantly different from ward staff.

\section{CONGLUSIONS}

The results of this investigation replicate those of an exploratory study comparing subjects with major depressive syndromes to non-depressed subjects (7). This follow-up study utilized a different medical center population and a different method of time series analysis. As in the exploratory study, we found that the major depression group demonstrated ultradian cycles of greater amplitude than controls. Again, we found no significant difference between groups in ultradian cycle period. Cycle lengths were five hours for both groups in the original investigation and three to four hours for the groups in this follow-up study. These cycle lengths are more rapid than the four to six hour cycles of mood reported in normal male subjects (6).

In this study we found that the three hour periodicity was most evident between 2:00 p.m. and 8:00 p.m. As evidenced by Figure 1 and Table 2, a concurrent six hour cycle harmonic may have a significant effect on morning mood. The three to four hour mood cycle, however, appears to account for the greatest amount of intra-daily mood variability based on visual inspection and spectral analysis of time series data. The absence of a morning mood peak in the depressed group may be a characteristic 


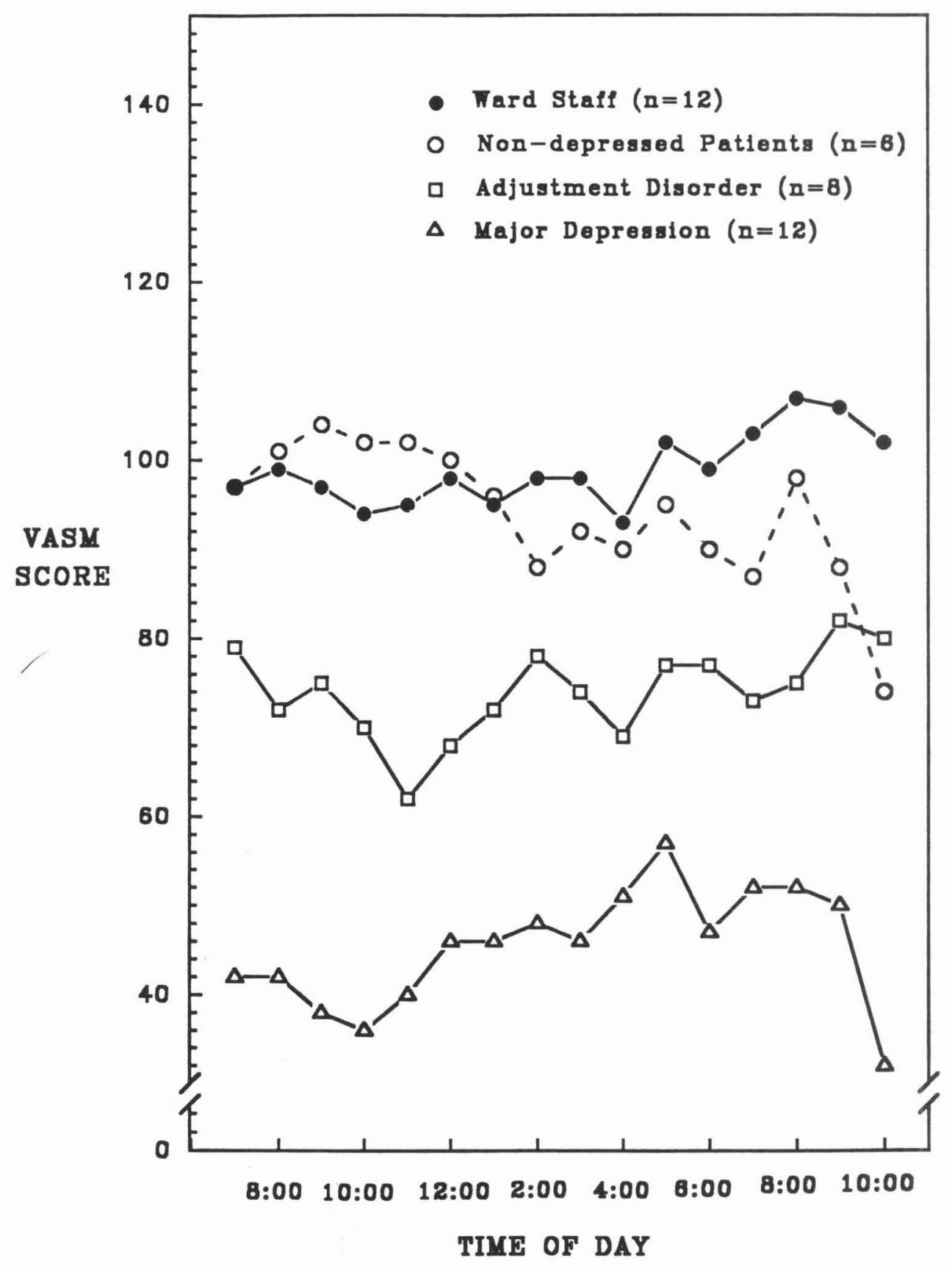

FIGURE 1. Time series data plots of visual analog scale of mood (VASM) scores versus time of day for depressed and non-depressed groups of subjects. 
TABLE 2.

Time of Ultradian Cycle Mood Peaks for Depressed and Non-depressed Groups

\begin{tabular}{lccccc}
\hline Group & \multicolumn{5}{c}{ Time of Mood Peaks } \\
\hline Ward Staff & $8 \mathrm{am}$ & $12 \mathrm{pm}$ & $2 \mathrm{pm}$ & $5 \mathrm{pm}$ & $8 \mathrm{pm}$ \\
Non-depressed Patients & $9 \mathrm{am}$ & - & $3 \mathrm{pm}$ & $5 \mathrm{pm}$ & $8 \mathrm{pm}$ \\
Adjustment Disorder & $9 \mathrm{am}$ & - & $2 \mathrm{pm}$ & $5 \mathrm{pm}$ & $9 \mathrm{pm}$ \\
Major Depression & - & - & $2 \mathrm{pm}$ & $5 \mathrm{pm}$ & $7 \mathrm{pm}$ \\
\hline
\end{tabular}

specific to this study population or may reflect a phenomenological distinction of major depressive episodes. The presence of a 12:00 p.m. mood peak is specific to the ward staff group, and may reflect the difference in mid-day meal experiences for this group.

In this follow-up study, we have also explored the specificity of ultradian mood cycle changes to depression using smaller groups of non-depressed and adjustment disorder depression patients. The finding of greater ultradian cycle amplitude in the adjustment disorder group suggests that greater cycle amplitude may be a characteristic of other depressive disorders. The absence of amplitude changes in the nondepressed psychiatric patient group suggests that this finding is not generalized to all psychiatric disorders. Further study is needed to confirm that greater ultradian cycle amplitude is specific to depressive syndromes, and not generalized to other psychiatric diagnosis (eg, anxiety disorders) or stressful conditions.

Many individual times series plots showed a wide range of cycle length and amplitude. Subjects demonstrating clear ultradian cycles on day 1 rarely showed the same pattern on day 2. We do not believe that this implies the absence of an endogenous rhythm, rather, that environmental variables may distort the ultradian cycle characteristics in a different manner on subsequent days. The high variability of ultradian cycle characteristics between and within subjects has been noted, repeatedly, in the study of ultradian cycles of EEG bands $(17,18)$. Studies of ultradian rhythms in metabolic factors have also noted poor stability of ultradian cycles and difficulty in controlling environmental conditions (19). Averaging of group hourly

TABLE 3.

Means and Standard Deviations (in parenthesis) for Ultradian Cycle Characteristics of Depressed and Non-depressed Groups

\begin{tabular}{lcc}
\hline Group & $\begin{array}{c}\text { Cycle Length } \\
\text { (hours) }\end{array}$ & $\begin{array}{c}\text { Cycle Amplitude } \\
\text { (VASM units) }^{\mathrm{a}}\end{array}$ \\
\hline Ward Staff & $3.3(0.6)$ & $4.0(3.1)$ \\
Non-depressed Patients & $3.7(2.1)$ & $5.2(2.3)$ \\
Adjustment Disorder & $3.7(1.1)$ & $8.7(4.6)^{\mathrm{b}}$ \\
Major Depression & $4.0(1.4)$ & $8.4(4.1)^{\mathrm{b}}$ \\
\hline
\end{tabular}

${ }^{\text {a VASM }}=$ Visual Analog Scale of Mood.

${ }^{\mathrm{b}} \mathrm{p}<0.05$, significant difference from ward staff using Mann-Whitney comparison. 
measurements may significantly reduce the interference of these variables, yielding a common underlying cycle.

Observation of peak and trough times in the present study reveals that peaks generally occur near meal times. Some investigators have noted that carbohydrates increase insulin levels, leading to changes in brain tryptophan ratios and increased serotonin production, which may elevate mood (20). Others have reported a bi-phasic pattern of beta-endorphin elevation after meals, with the first peak occurring 5 minutes after the meal and the second occurring approximately 90 minutes later (21). Biochemical analyses are needed to determine if levels of these factors correspond to ultradian cycles of mood. Such analyses may lead to a greater understanding of mood control.

Affective disorders may also involve a dysregulation of ultradian and circadian cortisol cycles. One study has reported cortisol secretion cycles of three and four hours for normal and depressed groups, respectively (22). Although length of cycle was not significantly different between groups, the magnitude of cortisol secretions were significantly greater in the depressed group. One may speculate that the three to four hour cycles of cortisol secretions, noted in that study, may correspond to the three to four hour cycles of mood noted in the present study, and that the greater magnitude of cortisol secretory episodes may correspond to greater mood cycle amplitude. This hypothesis is supported by a study of diurnal cycles of mood which found that cortisol levels correlated with mood changes in depressed patients but was unrelated to mood curves of non-depressed subjects (23).

In a separate analysis of this data, focusing on diagnostic issues of adjustment disorder depressions, we have reported that intra-daily variability of $\operatorname{mood}($ IDVM) is significantly greater in adjustment disorder group than in the other three groups (manuscript under review). Based on this finding, one may infer that the mood patterns of patients with adjustment disorder depression do not adhere as well to the underlying ultradian cycle pattern. This is consistent with the observation that adjustment disorders are associated with strong reactivity to environmental stimuli.

Although the presence of ultradian cycles was clearly demonstrated in all groups, some limitations to this study are noted. Sex and age differences were not well matched between groups. The use of medications, nicotine, caffeine and other food items was not controlled. Due to the long half-lives of antidepressant medications, however, we do not believe that this factor significantly effected findings. Further studies may benefit from greater control of these and other mood-altering variables. The number of patients in the non-depressed and adjustment disorder patient groups was relatively small and findings from these groups should be considered preliminary. A non-parametric statistical test was used to ensure a conservative probability statement. A larger number of patients and further restriction of the populations studies may permit a clearer impression of underlying mood cycles. Specificity of ultradian cycle changes in depressive disorders may be further assessed by examining non-psychiatric inpatients and psychiatric outpatients, who would not be subject to the same synchronizing effects of zietgebers (environmental cues) on an inpatient psychiatry ward. 
In conclusion, several observations are made. First, mood variation over the course of the day does not appear to be chaotic or completely dependent upon environmental changes. Rather, we have found that underlying mood rhythms of mood may form the basis for these changes. The underlying ultradian cycle of mood may be disrupted by environmental stimuli, resulting in mood cycle arrhythmias. However, the underlying cycle is revealed by averaging hourly mood scores of groups. At this point it is not possible to determine if ultradian cycles of mood are regulated by endogenous clocks, environmental stimuli, or an interaction of the two factors. Second, we have found that ultradian cycle amplitude was greater in a major depressive episode and adjustment disorder with depressed mood groups than in a ward staff group. It should also be noted that the ultradian cycles represent subtle changes in baseline mood state, and that these cycles may be more prominent in afternoon and evening hours. Repeated assessment of mood over the course of the day in the inpatient setting and varied appointment times in the outpatient setting may be useful to obtain an accurate assessment of mood.

\section{REFERENCES}

1. Klein R, Armitage R: Rhythms in human performance: one and one-half hour of oscillations in cognitive style. Science 1979; 204:1326-1327.

2. Lovett-Dovst JW, Payne WD, Podnie KS: An ultradian rhythm in reaction time in man. Neuropsychobiology 1978; 4:93-98.

3. Bossom J, Natelson BH, Levin BE, Stokes PE: Ultradian rhythms in cognitive functions and their relationship to visceral processes. Physiol and Behav 1983; 31:119-123.

4. Hayashi M, Hori T: Basic ultradian components of daytime sleepiness in human subjects. Japanese Psychological Research 1990; 32:128-136.

5. Lavie P, Sherson A: Ultrashort sleep-walking schedule, I: Evidence of ultradian rhythmicity in sleepability. Electroenceph Clin Neurophysiol 1981; 52:163-174.

6. Tsuji Y, Fukudu H, Okuno H, Kobayashi T: Diurnal rhythm of alpha wave activity and mood. Electroenceph Clin Neurophysiol 1985; 52:543.

7. Hall DP, Sing HC, Romanoski AJ: Identification and characterization of greater mood variance in depression. Am J Psychiatry 1991; 148:1341-1345.

8. Bearsma DGM, Daan S, Van den Hoofdakker RH: Distribution of REM latencies and other sleep phenomena in depression as explained by a single ultradian rhythm disturbance. Sleep 1984; 7:126-136.

9. Buysee DJ, Jarrett DB, Miewald JM, Kupfer DJ: Greenhouse JB: Minute-by-minute analysis of REM sleep timing in major depression. Biol Psychiatry 1990; 28:911-925.

10. Folstein MF, Luria R: Reliability, validity and clinical application of the visual analog mood scale. Psychol Med 1973; 3:479-486.

11. Luria RE: The validity and reliability of the visual analog mood scale. J Psychiatr Res 1975; 12:51-57.

12. Hamilton M: A rating scale for depression. J Neurol Neurosurg Psychiatry 1960; 23:56-62.

13. Monk TH, Buysee DJ, Reynolds III CF, Jarrett DB, Kupfer DJ: Rhythmic and homeostatic influences on mood, activation and performance in young and old men. J Gerontol 1992; 47:221-227.

14. Sollberger A: Biological Rhythm Research. New York: Elsevier, 1965. 
15. SPSS/PC and Trends. Chicago, SPSS Inc, 1990

16. Hayes WL: Statistics 3rd ed. New York: Holt, Rinehart and Winston, 1981.

17. Ortega SM, Cabrera MC: Ultradian rhythms in the EEG and task performance. Chronobiol 1990; 17:183-194.

18. Okawa M, Matousek M, Petersen I: Spontaneous vigilance fluctuations in the daytime. Psychophysiology 1984; 21:207-211.

19. Lloyd D, Stupfel M: The occurrence and function of ultradian rhythms. Biol Rev 1991; 66:275-299.

20. Toornviet AC, Pijl H, Meinders AE: Food and mood: the central connection. Neth J Med 1992; 41:45-47.

21. Matsumura M, Fukuda N, Saito S, Mori H: Effect of a test meal, duodenal acidification, and tetragastrin on the plasma concentration of beta endorphin-like immunoreactivity in man. Regul Pept 1982; 4:173-181.

22. Halbreich U, Asnis GM, Shindledecker R, Zumoff B, Nathan S: Cortisol secretion in endogenous depression. Arch Gen Psychiatry 1985; 42:909-914.

23. von Zerssen D, Doerr P, Emrich HM, Lund R, Pirke KM: Diurnal variation in mood and cortisol rhythm in depression and normal states of mind. Eur Arch Psychiatry Neurol Sci $1987 ; 237: 36-45$. 